not again seen. It is certain, therefore, that it must be very rare and local. Since the various species of Hetarius occur only with species of Formica or very rarely (H. minimus Fall) with species of Lasius, the occurrence of Melanetarius in the colonies of a Myrmicine ant is additional evidence, if it were needed, that Fall was right in regarding this beetle as the type of a distinct genus and not as an aberrant species of Hetarius.

\title{
THE SOUND-MAKING OF DIPTERA AND HYMENOPTER.
}

\author{
By C. E. Peniberton, \\ Stanford University, California.
}

That many Diptera and Hymenoptera produce sounds in two distinct ways has been an accepted belief for a long time. One of these ways is by the rapid ribration of the wings in the air; the other one is by the forcible inspiration and expiration of air through the spiracles, especially the thoracic ones.

The production of insect sounds by organs other than the wings was probably first noted by Aristotle when he said that the trachere were set in ribration by rapid in-and out-rushings of air causing a vibration somewhat similar to that produced by certain reed instruments.

Dr. H. Landois in 1867 in a very complete and exhaustive paper on the sounds and sound apparatus of insects deroted considerable attention to the Diptera and Hymenoptera. He made some elaborate explanations to prove that sounds were produced by certain viluratory portions of the spiracles, and performed a number of experiments to verify his explanations.

Burmeister also has advanced the theory that flies produced sounds by forcing air violently through the spiracles thus producing a vibration lond enough to be heard, and similar theories have been advanced by others. Landois's work however is still probably the standard.

Landois experimented with the house fly, (Musca domestica) a flower fly (Eristalis tenax), a dung fly (Scatophaga stercoraria), 
certain gnats, and a few other flies; also with a bumble bee, honey bee and certain wasps and hornets. With all he came to the same conclusion, namely, that besides the humming sound produced by the vibration of the wings in the air, another finer, higherpitched sound was produced, not by the wings but by an apparatus connected with the spiracles and trachere, usually the thoracic spiracles only. He found that by stopping the openings of the spiracles humming ceases, or becomes so feeble as to be hardly perceptible.

In one family of flies, howerer, (Stratiomyida), in which the thoracic stigmata are not strongly developed, no humming sounds could be detected other than those produced by the wings. The stigmata were similar in structure to all others examined, but not so strongly developed.

It is interesting to note that Landois seems to find in those insects which hum loudest with their spiracles, the strongest developed spiracles to be found in all. These are, according to Landois, excellently developed for sound production. The external opening of the spiracle is covered with hairs and leads to an enlargement at the commencement of the trachea and immediately behind the spiracle. This enlargement serves as a sounding box. A folded membrane, called the vocal membrane and forming lips or curtains more or less plaited and fringed, is placed between the edges of the spiracle and the sounding box and, when vibrated by violent rushing of the air, produces sound. This theory has been carefully worked out by Landois and has been generally accepted as fact.

Having performed a number of experiments with certain Diptera and Hymenoptera, and having obtained results in exact contradiction to those of Landois, I venture to state these results, offering them to entomologists for what they are worth.

Despite the weight of testimony which seems to favor the theory of the spiracular voice, I cannot aroid the conclusion, from these observations of my own, that there has been some curious mistake about it all. My experiments with several species of Syrphidæ (Eristalis tenax in particular) the house fly, honey bee and the bumble bee, show that these insects do not produce audible sounds by vibration of any portion of their spiracles or trachex, but that all sounds of the nature of humming or buzzing produced 
by them are made solely by the wings, either by their vibration in the air or by striking the wing bases against the body wall.

In all the experiments I have kept constantly in mind Landois's theory and all my experiments have been performed in an attempt to verify it. However, not in a single instance have the results pointed in any way toward Landois's conclusions.

The following are the experiments and observations made on Eristalis tenax, similar ones with similar results having been made on several other Diptera and Hymenoptera.

\section{Experiment I.}

A fresh, living achult was held by the legs allowing free motion with the wings. Two sounds were produced, one low when the inseet attempted to fly, and which was made simply by the vibration of the wings in the air, and the other about an octave higher, which was produced when the fly held the wings in a resting position and vibrated or trembled them very rapidly. This highpitched note was made by the striking of the wing-bases against the body-wall immediately below and of the wing-bases. A proof for this was given when the wings were cut off close to the bases and the same pitch of note was sounded. A paper strip placed against the tips of the trembling wings so as to act as a sounder, increased the strength of the note which the wing-bases produced.

\section{Experiment $I I$.}

The wings were cut off close to the body and the insect held by the legs as before. A loud, high-pitched buzz was produced. While producing the sound the wing-stubs were seen to be vibrating rapidly. Upon examining the spiracles while the sound was given, no external activity could be seen about them either in the hairs surrounding the opening or in the normal appearance of the spiracles while the insect was quiet. When a needle was placed against the vibrating wing-stubs the sound always ceased. $\mathrm{By}$ cementing the wing-stubs to the body no sound was made, though the spiracles were open and untouched.

Thus if the fly produces this high-pitched note by means of the spiracles it must be done only when the wings or wing muscles are free to act. 


\section{Experiment III.}

To prove that the spiracles have nothing to do with this note and that they are not needed in connection with the wing muscles in the sound production, the abdomen was cut off, likewise the head, and the thoracic spiracles securely cemented with collodion. Under these conditions the free wing-stubs still vibrated a little and produced the familiar buzz for a short time. By leaving the head intact in this experiment the note was as strong and clear as in a fresh uninjured specimen. A fresh fly with all spiracles securely closed and wings cut off', can be made to produce the loud hum and stop at will by holding or releasing the wing-stubs with a needle.

In another case the thoracic spiracles were completely destroyed with a needle, and the abdomen cut off, but the wings left free. The usual high-pitched buzz or hum was still produced.

Now, combining the fact that no sound, in any single case, was produced with spiracles open and wings secured from action, with the fact that sound, high and clear, was produced in every case with wings cut off or intact, but free at the base, even though all the spiracles were securely closed, we have, it seems to me, positive proof as to the cause of all the audible sounds produced by this fly.

A further experiment was made which verifies in a way what has already been proved.

The wings were pulled from an adult in such a manner as to remove them completely, leaving no traces of the bases. No sounds were produced. Landois believed to have done this, but seems only to have cut the wings off as closely as possible. It would be impossible to cut off the wings without leaving some very small portion which would be large enough to vibrate and produce a sound.

The above experiments were carefully repeated several times with the same results in every case. They seem to prove quite conclusively that the supposed sound of the spiracles is mercly a buzzing of the wing-bases or a striking of them against a portion of the body-wall adjoining them. The well-adapted character of the spiracles for the production of sound if air could be very violently forced through them, combined with the confusing fact that the same pitch of sound is produced both with the wings cut 
off and intact, might easily lead one to conclude that the sounds were produced by some other organ than the wings.

The question may well be asked, "Why are the spiracles so modified and complex as Landois considers them?" It must be taken into consideration that the spiracles are comparatively large openings to a very delicate and vital tracheal system, which should be safely guarded at its openings against the entrance of dust particles. In most cases they are protected by a dense growth of hairs but often are not, as for example in the honey bee. The thoracic spiracles of the honey bee are poorly protected externally but within the opening this folded membranous curtain, or so-called rocal membrane, acts undoubtedly as a screen against the entrance of dust, etc.

The work described in this paper was done in the Entomological Laboratory of Stanford University.

\section{THE STRIDULATIONS OF TWO INTERESTING LOCUSTID A. ${ }^{1}$}

\section{By H. A. Allard,}

U. S. Department of Agriculture, Washington, D. C.

The writer's first night collecting on Plummer's Island, near Washington, D. C., August \$5, 1909, made him accuainted, for the first time, with the stridulation of Atlanticus pachymerus Burmeister. It was singing after dark very close to the ground on a dry, rocky, thinly-wooded hillside. The notes of this oddlooking locust have the same lisping character as an Orchelimum. The phrases are brief, but rapidly repeated, with irregular intervals of silence intervening, sh-sh-sh-sh-sh-sh-sh-sh-sh-sh-shsh-sh-sh. One is reminded of the prolonged, lisping phrases of Orchelimum molossum Rehn. Several times, while watching the insect stridulate by lantern-light, the writer lisped an approach to its notes and got an immediate response. The grayish brown coloration of this locust is well adapted to its environment of dead

${ }^{1}$ Identified by Mr. A. N. Caudell of the U. S. National Museum. 

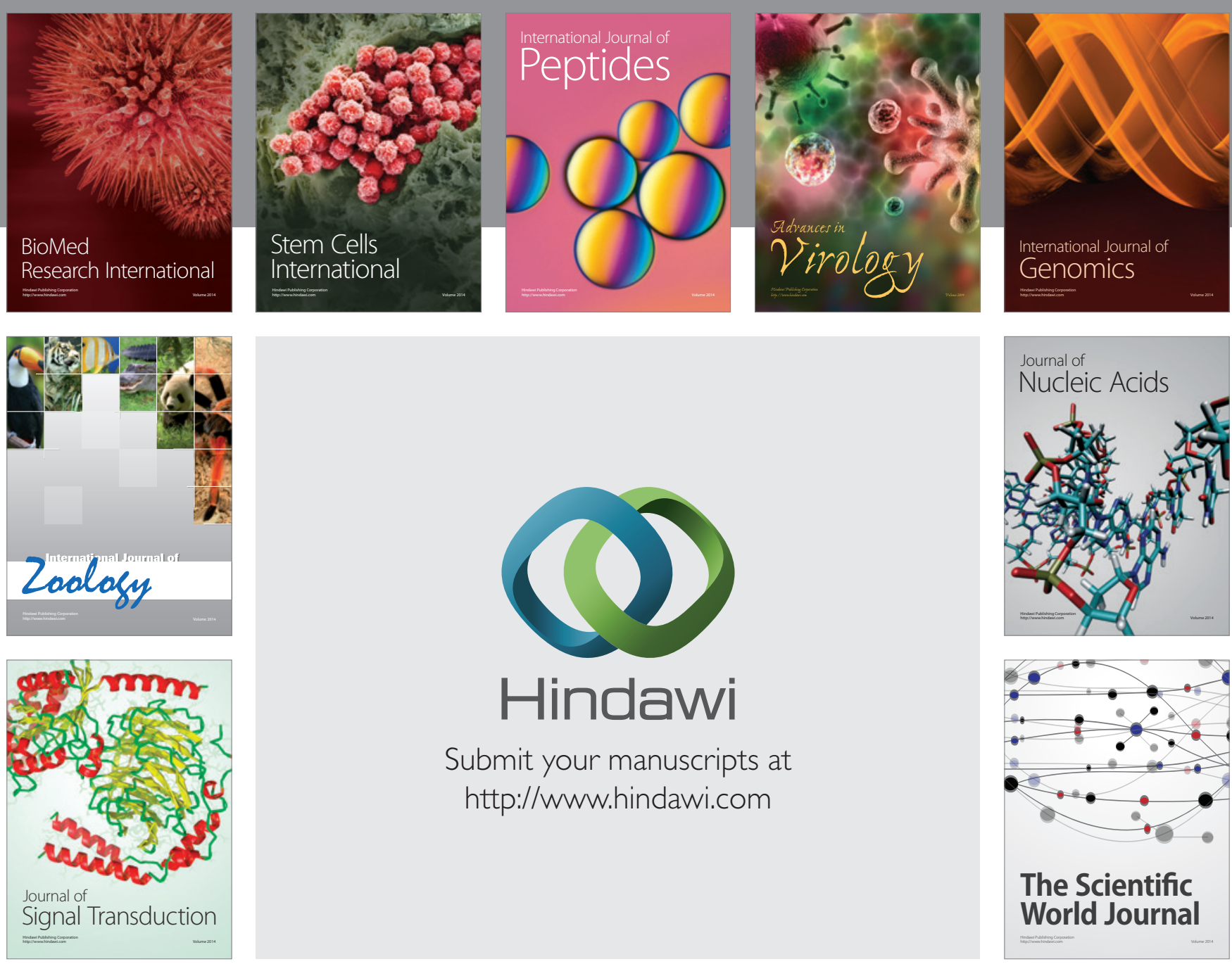

Submit your manuscripts at

http://www.hindawi.com
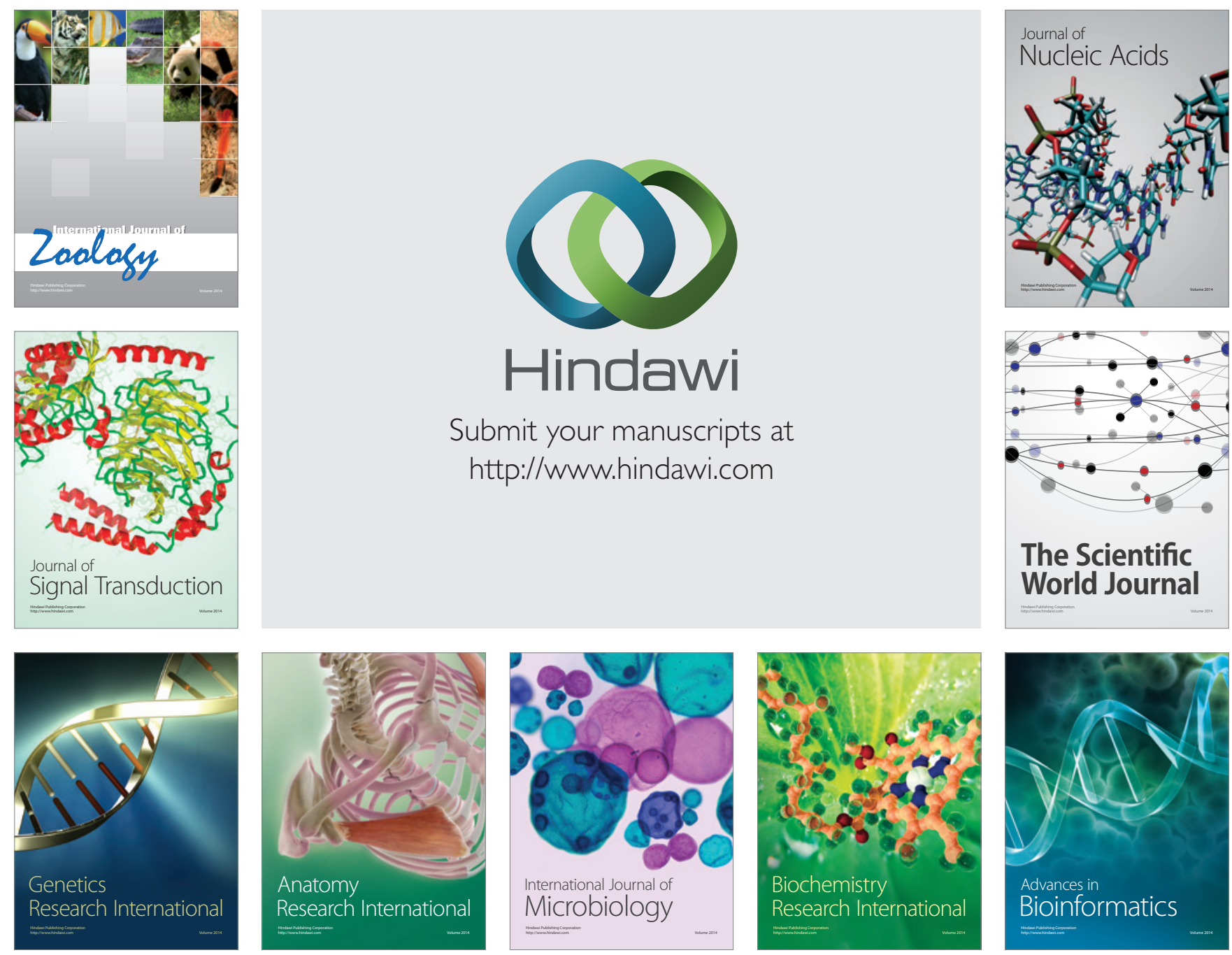

The Scientific World Journal
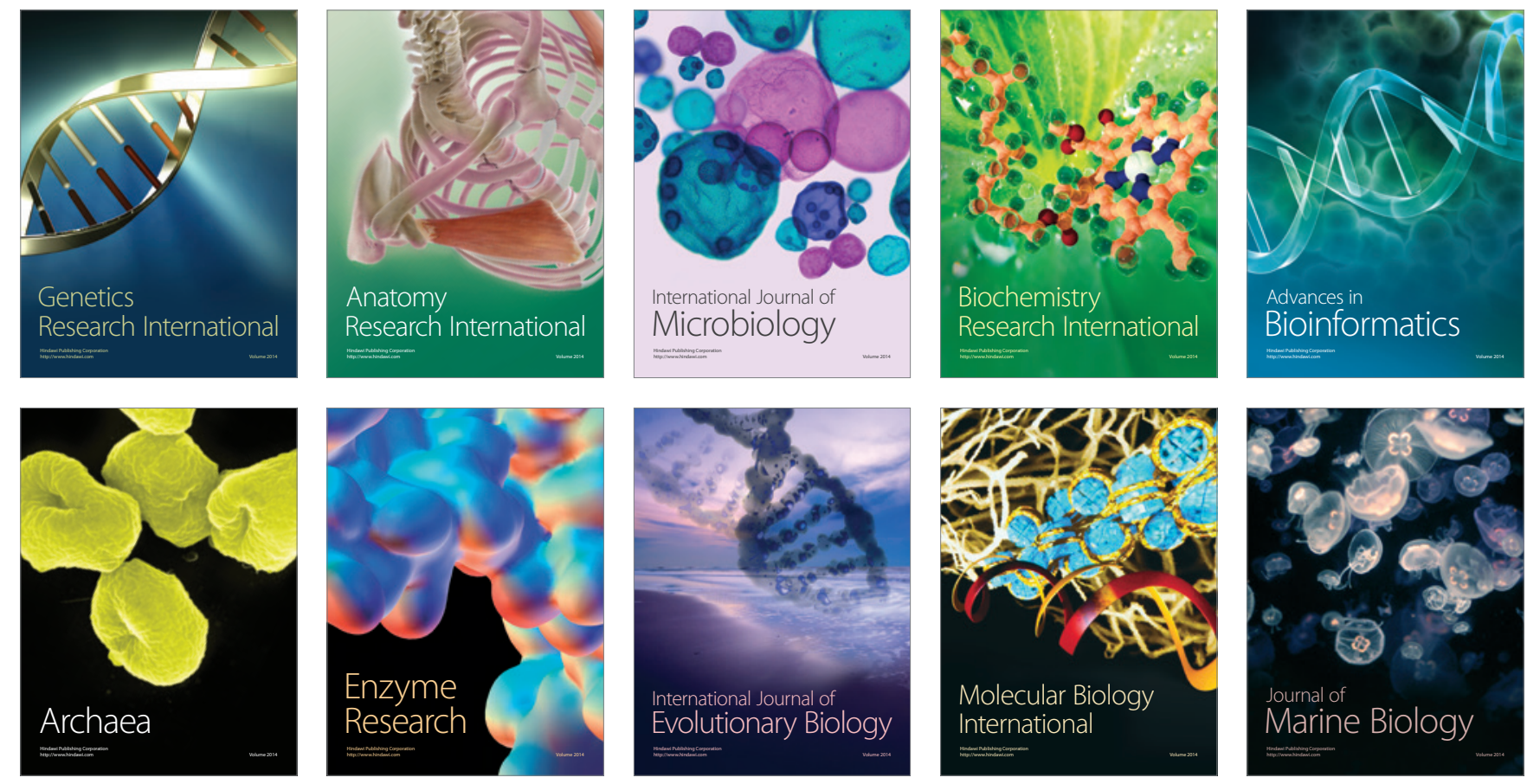